\title{
Sobre el componente valorativo de los predicados verbales en los debates sobre el lenguaje no sexista y los recursos gramaticales ${ }^{1}$
}

\author{
On the evaluative component of verbal \\ predicates in debates about non-sexist language, \\ and grammatical resources
}

\author{
Ma Antonia Martínez Linares \\ Universidad de Alicante, Alicante, España \\ antonia.martinez@ua.es
}

ACCESO ABIERTO / OPEN ACCESS

Cita: Martínez Linares, Maㅡ Antonia (2020). Sobre el componente valorativo de los predicados verbales en los debates sobre el lenguaje no sexista y los recursos gramaticales. Textos en Proceso, 6(2), pp. 107-127.

https://doi.org/10.17710/tep.2020.6. 2.8mamartinez

Editoras: Susana Guerrero Salazar y Carmen Marimón Llorca

Recibido: 10/10/2020

Aceptado: 02/11/2020

Conflicto de intereses: La autora ha declarado que no posee conflicto de intereses.

Copyright: () Ma Antonia Martínez Linares. Esta obra está bajo licencia Creative Commons Reconocimiento 4.0

\section{Resumen}

Este trabajo tiene por objeto indagar en las valoraciones negativas que aportan algunos predicados verbales sobre el uso de los dobletes y otros recursos gramaticales tendentes a extender el lenguaje inclusivo, pero también sobre quienes los rechazan o los promueven. Para ello, se han analizado los componentes valorativos de carácter negativo que incorporan los predicados en textos procedentes de blogs, artículos de prensa y de revistas lingüísticas que reflejan dos posturas encontradas sobre esos temas. El análisis ha permitido subrayar algunas de las ideas o creencias compartidas desde ambas posiciones respecto a la "otra parte"; ha posibilitado asimismo constatar que las valoraciones negativas no se ciñen a los efectos que esas propuestas gramaticales puedan tener en el funcionamiento de la lengua, aun cuando este aspecto sea uno los objetos principales de la crítica para una de las partes. De conformidad con las implicaciones sociales del problema, ambas partes hacen extensivas sus valoraciones negativas al proceder de colectivos, instituciones, personas, que apoyan o critican las propuestas y a los efectos que puede tener esa manera de actuar en la sociedad.

Palabras clave: doblete de género, recursos gramaticales, predicado verbal, valoración negativa, lenguaje no sexista.

\footnotetext{
${ }^{1}$ Este trabajo se enmarca en los Proyectos I+D+i PID2019-107265GB-I00 El columnismo lingüístico en la prensa española desde sus orígenes. Análisis multidimensional, caracterización y aplicaciones (METAPRES-COLING) e I+D+i (PAIDI 2020) El discurso metalingüístico sobre "mujer y lenguaje" en la prensa española: Análisis del debate lingüístico y su repercusión social (DISMUPREN).
} 
Abstract

The aim of this work is to inquire into the negative assessments provided by some verbal predicates on the use of certain grammatical resources to extend inclusive language, like gender doublets, but also on those who reject or promote those resources. To this end, I have analyzed the negative value components provided by verbal predicates in texts from blogs, press articles and language journals reflecting two mixed positions on these topics. This analysis has highlighted some of the shared ideas or beliefs regarding "the others" from both positions. The analysis has also made it possible to verify that negative evaluations are not limited to the effects that these grammatical proposals may have on the functioning of the language, even when this aspect is one of the main objects of criticism for one of the sides of the debate. In accordance with the social implications of the problem, both parties extend their negative evaluations to the actions of groups, institutions, people who support or criticize the proposals and to the effects that this procedure may have on society.

Keywords: gender doublet, grammatical resources, verbal predicates, negative evaluation, no sexist language.

\section{Introducción}

Es evidente que los distintos aspectos relacionados con el "sexismo lingüístico"2 han sido y siguen siendo objeto de debates que han tenido su reflejo tanto en artículos y foros de lingüística como en la prensa. Son bien conocidas las polémicas en torno al diccionario como "recipiente de ideología" (Guerrero Salazar, 2019) y las definiciones peyorativas y ofensivas para las mujeres. Pero parece claro que el debate, avivado, como indica por ejemplo Medina Guerra (2016, p. 218), tras la publicación del informe "Sexismo lingüístico y visibilidad de la mujer" presentado por Ignacio Bosque (Bosque, 2012), se ha hecho extensivo a otros aspectos más "gramaticales", como la legitimidad del "masculino genérico" para abarcar el masculino y el femenino de un modo "neutro" y la alternativa, más "inclusiva" y menos ambigua ${ }^{3}$, que brindan los desdoblamientos de los términos en masculino y femenino.

No pasa desapercibido que en las discusiones en torno a estas cuestiones se entremezclan razones de carácter ideológico o afectivo con argumentos de tipo lingüístico; incluso hay quien opina que en muchos casos parece tener más peso el componente ideológico y afectivo que el lingüístico (Medina Guerra, 2016, p. 218; Cabeza Pereiro y Rodríguez Barcia, 2013, p. 8). Para Mendívil (2013), por ejemplo, aunque en las polémicas sobre el uso no sexista del lenguaje intervienen con

\footnotetext{
${ }^{2}$ Entendido, por ejemplo, como "el conjunto de prácticas del lenguaje que realizan los seres humanos que invisibilizan, excluyen o discriminan tanto a las mujeres como a los grupos de la diversidad sexual, social y étnica" (Piña Laynez y González Poot, 2018, p. 375); o como "la distribución inicua de prácticas lingüísticas a partir de la preeminencia de un género gramatical con base en motivaciones ideológicas de índole cultural y tradicional" (Cabeza Pereiro y Rodríguez Barcia, 2013, p. 8). Según señalan Bengoechea (2008, p. 38) y Guerrero Salazar (2019, p. 46; 2010, p. 32), las críticas al sexismo lingüístico se avivan en la década de los 80 .

${ }^{3}$ De conformidad con Medina Guerra (2016, p. 188), el masculino genérico con referente humano puede resultar ambiguo debido "al doble valor que tiene en la designación de personas y animales: uno específico (con referente normalmente al sexo masculino) y otro genérico (con referente a ambos sexos)".
} 
posiciones encontradas prestigiosos lingüistas, subyace en ellas una cuestión ideológica más que lingüística. Desde el punto de vista de Uría (2012) en los debates lingüísticos se han mezclado "reproches de diversa índole" y a veces da la impresión de que se enfrentan "las feministas, que defienden los derechos de las mujeres, con unos especialistas en lingüística, indiferentes a los mismos" ${ }^{4}$.

Ya se centren en aspectos lingüísticos, ya involucren cuestiones sociales o de otro tipo, los debates incorporan una alta carga valorativa que permite inferir algo de la "ideología lingüística", de las creencias compartidas que subyacen a los puntos de vista antagónicos sobre las propuestas relacionadas con el lenguaje no sexista.

Así, abundan en los discursos que giran en torno a este tema los elementos que "en sí mismos" aportan juicios y valoraciones subjetivas de sentido positivo o negativo (Llamas Saíz, 2013, p. 195) respecto a propuestas lingüísticas o a los actores que las sustentan: partidos políticos, sindicatos, representantes de posturas "feministas", las "guías" de lenguaje no sexista y quienes las han elaborado o la Academia. Por ejemplo, como subraya Guerrero Salazar (2019, p. 55), en el marco de las polémicas sobre el "sexismo" del diccionario, "los defensores del feminismo tildan a la Academia de machista, misógina, anacrónica, refractaria, elitista".

La valoración -que incluye apreciaciones y juicios, de conformidad con el concepto planteado, por ejemplo, por Llamas Saíz ${ }^{6}$ (2013)- se construye indudablemente a través de diversas categorías (sustantivos, adjetivos, verbos, adverbios), integradas, a su vez, en distintos constituyentes oracionales.

Por ejemplo, en el enunciado que se incluye más abajo el juicio negativo sobre la postura de la Academia a propósito del masculino genérico se configura mediante el adjetivo "tenaz" - equivalente a "firme", pero también a "obstinada", "terca", "pertinaz"- que califica la "insistencia" de la RAE, así como a través el significado del verbo socavar, cuyo objeto son los "esfuerzos" para conseguir la igualdad:

1) Cabe destacar que la insistencia tenaz de la RAE en la defensa del masculino "genérico" socava parte de los esfuerzos políticos expresados en primer lugar por la Ley Orgánica 3/2007 "para la igualdad efectiva de mujeres y hombres” (Becker, 2019, p. 5)

En el siguiente, el uso del verbo embaucar, con el componente de "engaño" que incorpora, deja patente la valoración asimismo negativa que le merece al autor la propuesta de extensión de los dobletes:

\footnotetext{
${ }^{4}$ Figuran sin número de página las citas procedentes de trabajos, blogs, columnas, artículos de periódico tomados de Internet. En el apartado de "referencias" se incluyen las direcciones en las que se han obtenido.

${ }^{5}$ Según Marimón y Santamaría (2019, p. 1), las ideologías lingüísticas son sistemas de ideas que "se materializan en forma de opiniones sobre distintos aspectos del lenguaje que van desde su propia naturaleza a la norma lingüística, la identidad, el purismo, el bilingüismo, el contacto de lenguas, la autoridad académica, etc.”.

${ }^{6}$ Llamas Saíz parte de la Teoría de la Evaluación, elaborada principalmente por J. R. Martin y P. R. R White (véase Martin y White, 2005). En un sentido amplio, caracteriza la valoración o evaluación como "un tipo de información que, en el discurso, incluye la expresión lingüística de sentimientos, creencias y valores" (Llamas Saíz, 2013, p. 194). Abarca la "actitud" que "puede subdividirse igualmente en tres subsistemas: i) afecto, ii) juicio y iii) apreciación. Pero, como ella misma sugiere, esos subsistemas no se prestan a una delimitación clara. De ahí que apreciaciones y juicios acaben confundiéndose en el discurso (2013, p. 203).
} 
2) Y al hablante se lo intenta embaucar con el gusanillo de que sin esta práctica peca de discriminador (Roca, 2012).

En este otro, por último, el juicio contrario al recurso gramatical que se comenta se conforma mediante su catalogación como "tarea absurda", unida el hecho de que se atribuya a su aplicación no solo "dejar numerosos cabos sueltos y manifiestas contradicciones", sino también "poner en riesgo" el objetivo inclusivo que se perseguía:

3) Extrapolar o aplicar los consejos sobre el uso de esos cinco pronombres al complejo sistema de concordancias de género del español es una tarea abocada a dejar numerosos cabos sueltos y manifiestas contradicciones, una tarea absurda que, de hecho, pone en riesgo el lícito objetivo de hacer más visibles a las mujeres en el uso del lenguaje (Mendívil, 2013).

Todos estos enunciados evidencian que, en efecto, las valoraciones se pueden construir mediante diferentes categorías, pero también ponen de manifiesto que una parte importante de esa valoración puede venir dada por el verbo -o composicionalmente por el verbo y sus complementos ${ }^{7}$ - como parte nuclear de la predicación con que atribuimos "valores a los actores y sus acciones" (Díaz, 2011, p. 7), además de características, estados, acciones o procesos a los sujetos.

Este trabajo tiene por objeto indagar en la valoración negativa que puede aportar esa parte nuclear de los predicados verbales respecto a las propuestas relacionadas con el lenguaje no sexista en el ámbito gramatical ${ }^{8}$, en especial el recurso a los desdoblamientos frente al masculino genérico. Para ello se ha reunido un pequeño corpus de blogs, columnas lingüísticas, artículos de prensa y de revistas lingüísticas que reflejan dos posturas encontradas sobre tales temas; grosso modo, la de quienes se sitúan en la línea del informe de Bosque y de la Academia y la de quienes apoyan los usos encaminados a extender el lenguaje no sexista, rechazando en mayor o menor medida el punto de vista de la Academia. Se han ido destacando los componentes evaluativos de sentido negativo aportados por verbos o, en su caso, por frases verbales complejas utilizadas para atribuir "acciones" y valoraciones ya sea a las normas o propuestas lingüísticas, a los informes o a las guías, y a su efecto -beneficioso, perjudicial- en la lengua, en los hablantes, en la sociedad, ya sea a quienes las proponen, las rechazan o las sustentan. El análisis ha permitido asimismo destacar algunos lugares comunes, ideas o creencias respecto a "los otros" compartidos por quienes se sitúan en torno a esas dos líneas opuestas.

\section{En la línea del informe de la Academia}

\subsection{Los desdobles y su efecto sobre la lengua}

Como han apuntado diversos estudios sobre el discurso periodístico en español (Méndez García de Paredes, 2000, 2001; Casado Velarde, 2010; Escribano Hernández, 2009, entre otros), la presencia de diferentes fuentes informativas y la pluralidad de voces, en forma de declaraciones, relatos, reacciones verbales, son aspectos caracterizadores de este tipo de discurso, que es esencialmente polifónico.

\footnotetext{
${ }^{7}$ El peso del verbo en la predicación es variable y en cualquier caso hay que contar con el sentido que alcanza en composición con los complementos.

${ }^{8}$ Según Fábregas et al. (2012) "la gramática no se relaciona de ninguna manera obvia con diferentes actitudes culturales" a diferencia del léxico "donde se reflejan con cierta nitidez los prejuicios de una sociedad".
} 
Sin duda una de las ideas que se reiteran cuando se critica el recurso "abusivo" a los desdobles ${ }^{9}$ frente a un empleo no ambiguo del masculino genérico -es decir, un empleo que no se preste a una interpretación excluyente de la mujeres que ese uso resulta extraño al sistema gramatical, que se trata de algo forzado, no natural, y que por ello puede tener efectos nocivos, de distinto grado, para el buen funcionamiento de la lengua.

Los cambios no forzados, como la creación de formas femeninas para oficios que antes no las tenían, se presentan como un proceso positivo, una adaptación natural, que no provoca rechazo:

4) Es indudable también que estos usos están cambiando sin necesidad de que nadie legisle por ellos, y que secuencias que hace años se sentían como extrañas (la jueza, la Presidenta, la cancillera) se han ido acomodando en el uso (Fábregas et al., 2012).

Sin embargo, cuando se habla del uso de los desdobles considerados innecesarios se utilizan verbos o frases verbales que les atribuyen la peculiaridad de "obligar" a la lengua a adoptar un uso contrario a su funcionamiento normal; así los desdobles o quienes los propugnan o los aplican "fuerzan" "la lengua" o "los cambios" que la afectan; "chocan" con el sistema, "van en contra" de "la economía" o "pasan por alto" aspectos esenciales de la lengua:

5) Si allí los hablantes forzaban la lengua para que el femenino estuviera presente, en este caso son las propias mujeres quienes se aferran al uso de un masculino de escaso sentido en la sociedad actual (Azofra, 2012).

6) Y aun si el lingüista debiera hacer juicios morales, no sería posible ni deseable forzar los cambios mediante reglas que afecten al uso de la lengua (Fábregas et al., 2012).

7) "Si alguien intenta así forzar la lengua está abocado al fracaso", advierte Pedro Álvarez de Miranda, miembro de la RAE (Ruiz Mantilla, 2016).

8) Ni el castellano es una lengua "sexista" ni los dobletes son compatibles con su sistema. Peor aún, chocan frontalmente con él (Roca, 2012).

9) En tiempos que tienden a la síntesis, la tesis de la doble utilización de género añade otro problema. En opinión de Pedro Álvarez de Miranda, "los desdobles van en contra de la economía de lenguaje" (Ruiz Mantilla, 2016).

10) ¿Cuál era su idea de fondo? [...] las guías de lenguaje inclusivo, el empleo de sus recomendaciones no sólo en el registro formal sino también en el informal, en el escrito o en el hablado, pasan por alto fundamentos elementales de nuestro idioma (Rius, 2016).

La idea de la falta de naturalidad de los desdoblamientos se ve reforzada asimismo con el énfasis en la "artificiosidad" que se achaca a su empleo frente al uso "espontáneo" del masculino genérico. En el siguiente enunciado esa valoración descansa en la construcción formada por hacer y el predicativo ("más artificiosa") del OD:

\footnotetext{
${ }^{9}$ En buena parte de los textos examinados no hay una crítica a los desdobles en sí, ni al lenguaje inclusivo sino al abuso de los dobletes y a "las posturas más radicales" (Cabello Pino, 2019, p. 11).
} 
11) Además de infructuoso para el uso general del idioma, cabe preguntarse si esta clase de recomendaciones que hacen más artificiosa la expresión son deseables (Fábregas et al., 2012).

En estos otros son los complementos de "manera" o los modificadores de los nombres objeto del verbo ligero hacer y de fomentar los elementos con los que subraya la artificiosidad de los desdobles frente al uso "natural":

12) ¿A qué precio se puede cambiar ese uso que se ha convertido desde hace siglos en natural? A un precio político, creen muchos de los que observan con preocupación que se quiera revertir de una forma impuesta y un tanto artificial (Ruiz Mantilla, $2016)^{10}$.

13) No es infrecuente que se hagan todo tipo de recomendaciones artificiales en el lenguaje no espontáneo (Fábregas et al., 2012).

14) Por ello, las guías del llamado lenguaje no sexista no dejan de ser un brindis al sol que, en el mejor de los casos, afectarán a usos institucionales o a grupos que se vean en la necesidad de ser "políticamente correctos", y corren el riesgo de fomentar una modalidad lingüística artificial y especializada en determinados usos (Uría, 2012).

Ahora bien, los efectos negativos de ese recurso, que se percibe como ajeno al funcionamiento normal de la gramática del español, no se limitan a la artificiosidad. Se perfila como una amenaza, como un uso del que derivan efectos perjudiciales que obstaculizan el buen funcionamiento del idioma; los desdobles no solo hacen pesadas, farragosas, innecesariamente complejas las construcciones (alargan, complican, recargan "hasta límites estéticamente insoportables", hacen "cansina" la comunicación); además, perjudican, imposibilitan "mantener la consistencia", acarrean "ambigüedades y malentendidos", obligan "a decir algo distinto" de lo que se quería decir en realidad, abocan a interpretaciones erróneas, contradicciones e incorrecciones morfológicas y sintácticas:

15) Aquí se me ocurren varios problemas; en primer lugar, el de la concordancia: si los sustantivos van acompañados de adjetivos y estos también se duplican, el enunciado se alarga y complica. En un mensaje breve puede, a veces, usarse, pero resulta muy difícil de mantener en un texto largo o una conversación y hace que la comunicación resulte cansina y poco fluida (Uría, 2012).

16) Porque al final, con la pretensión de combatir el lenguaje sexista estamos perjudicando a la economía y corrección del lenguaje y convirtiéndolo en más feo y farragoso (Lucio, 2017).

17) Es posible mantener la consistencia del uso en textos escritos cuidadosamente revisados, a costa de cierto fárrago y artificiosidad en el estilo, pero no lo es en el uso oral (Mendívil, 2020, p. 62).

18) Valga como ejemplo para los amantes de la lógica clásica: se aconseja que sustituyan los cuantificadores universales (Todos los estudiantes) -que al marcar género forzarían un referente masculino, según estas guías- por distributivos (Cada estudiante) sin esa peligrosa marca de género. Para comprobar que esta sustitución nos ha obligado a decir algo distinto de lo que queríamos decir, compárese Todos los estudiantes vinieron juntos con Cada estudiante vino juntos, que es imposible (Fábregas et al., 2012).

\footnotetext{
${ }^{10}$ Son palabras de Álvarez de Miranda reflejadas por Ruiz Mantilla en su artículo.
} 
19) No se puede andar todo el día con los dobletes que, además, se utilizan mal. Muy aficionados a ellos son los populismos políticos que dicen eso de "los ciudadanos y las ciudadanas madrileños", lo que nos lleva a una grave incorrección sintáctica relativa a la concordancia (Rius, 2016).

20) No todas estas propuestas encaminadas a lograr el uso igualitario de la lengua han tenido el mismo grado de aceptación por la ciudadanía, pues algunas han sido totalmente ignoradas, y otras, que gozaron inicialmente de cierto calado en los distintos ámbitos de la comunicación social y especializada, no son ya frecuentemente empleadas debido a los múltiples inconvenientes que conlleva su puesta en práctica y a que revelan usos incorrectos de la lengua, pues suelen acarrear ambigüedades y malentendidos (Díaz Hormigo, 2018, p. 268).

21) Como consecuencia de la falta de naturalidad y dificultad de aplicación de las expresiones que recomiendan estas guías, se añade el peligro de que los textos legales que traten de seguirlas entren en contradicciones (Fábregas et al., 2012).

22) Quieren hacernos creer con sus guías de uso de lenguaje no sexista que la visibilidad de las mujeres pasa por desnaturalizar nuestro idioma con fórmulas rebuscadas, cuando no claramente atentatorias contra la morfología gramatical o sintáctica sin miedo alguno a recargar el discurso hasta límites estéticamente insoportables (Del Corral, 2012).

En definitiva, la extensión de los desdoblamientos puede acabar deteriorando el sistema gramatical ${ }^{11}$. Tal es la idea aportada en (22) por desnaturalizar y constituye igualmente un concepto que subyace a atentar, destruir, deteriorar, poner en riesgo, poner en jaque, producir estragos, así como a las metáforas socavar los cimientos de la lengua o devorar el bosque:

23) La duplicación sí podría hacerse, claro está, pero atentaría contra un principio básico de las lenguas como es el de la economía del lenguaje [...] (García Pérez, 2012).

24) Las lenguas se rigen por un principio de economía; el uso sistemático de los dobletes, como miembro y miembra, acaba destruyendo esa esencia económica (Seisdedos, $2018)^{12}$.

25) El idioma es un ecosistema. Si se altera de manera arbitraria, se deteriorará de manera incluso irreversible (Escolar, 2018) ${ }^{13}$.

26) No hay que olvidar que determinadas prácticas y recomendaciones de las citadas guías se plantean para hacer una llamada de atención sobre una situación de infravaloración de las mujeres [...], pero ello no debe poner en riesgo la utilidad del idioma como herramienta de comunicación y relación” (Manrique Sabogal, 2012).

27) Es una de las cuestiones que desde hace años preocupa de una manera creciente en la Real Academia Española (RAE), donde las tendencias sociales y políticas partidarias de eliminar lo que consideran un uso sexista del lenguaje ponen en jaque la estructura del idioma (Ruiz Mantilla, 2016).

\footnotetext{
${ }^{11}$ Algo atribuido asimismo a la utilización "no natural" de la terminación -e para abarcar masculino y femenino.

12 El texto corresponde a una entrevista con Darío Villanueva, director entonces de la Academia, publicada en El Pais (16-07-2018) por Iker Seisdedos.

${ }^{13}$ El texto pertenece igualmente a una entrevista con Darío Villanueva publicada por Arsenio Escolar en Archiletras (05-11-2018).
} 
28) Los dobletes, por tanto, representan un conato de incendio con potencia para devorar el bosque y producir así estragos inimaginables desde la lejanía y la ignorancia del terreno (Roca, 2012)

29) Ya han estado socavando esta sección de los cimientos de la lengua demasiado tiempo (Roca, 2016).

La argumentación en contra del recurso abusivo a los dobletes de la que forma parte el componente valorativo ilustrado por estos enunciados parece ceñirse al terreno lingüístico, dado que se trata de señalar efectos no deseados de determinadas fórmulas lingüísticas sobre el sistema gramatical. Pero, como se planteaba al principio de este trabajo, el debate en torno a estas cuestiones trasciende los límites de lo lingüístico y ese componente evaluativo acaba proyectándose sobre las entidades que proponen esas fórmulas y sobre las repercusiones que pueda tener su extensión en la sociedad, en los hablantes.

\subsection{Más allá del sistema gramatical}

Si en el anterior apartado se subrayaba la idea de que los desdobles o quienes los propugnan "fuerzan" la lengua, el hecho de que el debate no se circunscribe a cuestiones lingüísticas queda de manifiesto cuando la evaluación negativa que aportan los predicados tiene por objeto, de una forma más directa, explícita, las entidades que promueven estas formas de lenguaje no sexista o el efecto que pueden tener en las instituciones, en determinados colectivos; en definitiva, en la sociedad.

Por ejemplo, la idea de "imposición", proyectada anteriormente sobre la lengua, forma parte de la actitud hostil, coercitiva, coactiva, que se atribuye a quienes promueven esos usos gramaticales considerados extraños al funcionamiento normal de la lengua: presionan, imponen, legislan, intentan hacer cambios "a golpe de leyes"; y los afectados son ahora los hablantes, determinadas instituciones o colectivos, la Academia:

30) No quiero que sindicatos, centros laborales dependientes de un ministerio o comunidades autónomas, etcétera, presionen a trabajadores o aspirantes a utilizar el lenguaje de una forma determinada (Lindo, 2012).

31) En definitiva, aunque, tal como señalaba Violeta Demonte, no había una gran demanda social, desde ciertos sectores ideológicos llevaban años presionando para que el tema al menos sí que estuviese en la palestra (Cabello Pino, 2019, p. 11).

32) Esta preconcepción implícita parece entender que la gramática se hace a golpe de leyes, pero esto es radicalmente falso (Fábregas et al., 2012).

33) [La propuesta de adoptar la terminación -e] no surge como cambio "desde abajo" [...] sino como una propuesta "desde arriba", numéricamente minoritaria nacida de un grupo de clase media que busca imponer con marca en la lengua un valor en torno a un reclamo social (Moure, 2018).

Asimismo, mientras algunos de los enunciados antes citados hacían hincapié en la "artificiosidad" de los desdoblamientos y su efecto negativo en la construcción e interpretación gramatical, la apreciación negativa que sugieren la falsedad, el engaño, el encubrimiento, asociados al artificio, traspasa el ámbito de lo lingüístico cuando se atribuye a las intenciones de quienes proponen extender el uso de los dobletes u otras formas de forzar el sistema gramatical, como ocurría en el enunciado (2) con el uso del verbo embaucar. 
A este respecto cabe destacar, en primer lugar, la construcción de predicados con los que se achaca a quienes abogan por imponer determinadas fórmulas inclusivas la intención de intentar soslayar con sus propuestas asuntos sociales más relevantes, o de orientarlas a fines distintos de los realmente declarados. Esa es la nota negativa subyacente a manipular, sacar punta ${ }^{14}$, llenarse la boca ${ }^{15}$; a revestirse que en (37) convierte en simulación la "pátina de verdad y formalidad"16, y naturalmente a falsear que en (38) valora negativamente, mediante una comparación, la pretensión de que los lingüistas impongan a los hablantes, por razones no lingüísticas, usos extraños a la gramática:

34) Censurar y manipular la lengua de los ciudadanos es ridículo e intrusivo (Lindo, 2012).

35) Debe de ser frustrante la pretensión de sacar punta a estas cuestiones desde el feminismo en lugar de reflexionar serenamente sobre ellas desde el terreno en que solo cabe dilucidarlas, que es el de la gramática (Álvarez de Miranda, 2018a).

36) Es más cómodo llenarse la boca de "nosotros y nosotras" que cambiar realmente la sociedad para que la mujer esté más formada, más protegida laboralmente y tenga igualdad real de oportunidades (Lucio, 2017).

37) El doblete, sin embargo, aunque también incómodo, se reviste de una pátina de verdad y de formalidad que lo hace anzuelo ideal para captar adeptos (Roca, 2012).

38) Pero esta actitud normativista convertiría a los lingüistas en los únicos investigadores y científicos cuya tarea es la de preservar una pureza ideal en lugar de la de descubrir cómo funciona su objeto de estudio. Si un detective decide falsear sus informes porque el asesinato y la corrupción despiertan en él un rechazo moral, sería castigado penalmente (Fábregas et al., 2012).

En el mismo ámbito asociado a la falsedad, el encubrimiento, el engaño, hay que situar, por ejemplo, algunos usos de decir como evidencial o el empleo igualmente evidencial, no volitivo, de pretender, con el sentido, compartido con adjetivos y adverbios del mismo campo, de que lo pretendido se considera falso. Decir en el siguiente enunciado apuntaría a que "se discrepa con el conceptualizador" (Saeger, 2007, p. 271), a que cabe dudar de que los colectivos aludidos realmente se sientan discriminados:

39) No es que quite el sueño este caso específico, si no que en aras de una corrección política o de apoyar a colectivos que dicen sentirse discriminados, se propongan usos de género diferenciados: compañeros y compañeras; candidatos y candidatas (Ruiz Mantilla, 2016).

En este otro "pretende" parece cuestionar el objetivo declarado de la regla que aconseja usar "profesores y profesoras" o "profesorado":

40) Está claro que esa regla no tiene en cuenta el contexto y pretende luchar contra el sexismo confundiendo lenguaje sexista (donde lo que cuenta es el significado de las palabras) con género gramatical (Lucio, 2017).

\footnotetext{
${ }^{14}$ Implica atribuir un sentido malicioso a algo que no lo tiene.

${ }^{15}$ Se asocia a hipocresía y falta de coherencia con lo que abiertamente se manifiesta.

${ }^{16}$ Idea ratificada por la condición de "anzuelo ideal para captar adeptos".
} 
En los textos siguientes son el adjetivo pretendido y los adverbios evidenciales pretendidamente, supuestamente, los elementos que proyectan dudas sobre la correspondencia entre la realidad y lo denotado por la unidad que modifican (Torner, 2016, p. 252):

41) O, por llevar al extremo esa pretendida normativa, si me preguntasen por mi prole, ¿debo contestar que tengo "cinco hijos barra hijas", cinco "hij arroba ese" o me van a obligar a decir que tengo "cinco unidades"? (García Pérez, 2012).

42) No es ocioso recordar que si se aplicaran por completo las directrices de ese lenguaje políticamente correcto y pretendidamente "visibilizador" de la mujer no se podría hablar (García Pérez, 2012).

43) Por supuesto, decir cada vez Los niños y las niñas es perfectamente lícito y gramatical, pero lo que concuerde con tal sintagma volverá a ser masculino plural (aquí ya sin opción) y (supuestamente) volverá a ocultar a las mujeres, haciendo evidente lo contradictorio e innecesario del esfuerzo requerido (Mendívil, 2013).

Por último, la nota negativa que sugiere esa falta de coherencia entre los fines declarados y la realidad queda asimismo perfilada en los siguientes textos de Grijelmo mediante predicados que contrastan el uso de los dobletes en ámbitos sociales con connotaciones positivas y el hecho de que dejen de utilizarse cuando se tratan temas "de mal rollo", es decir, vinculados a cosas desagradables:

44) Ya se ve, pues, la distinta jerarquía de las palabras. Admiten duplicación "ciudadanos y ciudadanas", "magistrados y magistradas", "padres y madres"... Pero los dobletes desaparecen cuando el término implica mal rollo: los culpables, los intermediarios (Grijelmo, 2020).

45) En la crisis del coronavirus asistimos a un fenómeno similar. Quienes ocupan el espacio público se esmeran en decir "ciudadanos y ciudadanas", "todos y todas", "cada uno y cada una"; mientras se cuelan sin filtro "los más vulnerables", "los hospitalizados", "los infectados", "los mayores", "los fallecidos", "los enfermos" (Grijelmo, 2020).

En cualquier caso, no se agotan con los sentidos asociados a la imposición y el falseamiento las valoraciones negativas que aportan los predicados verbales sobre el proceder de quienes promueven las estrategias para extender el lenguaje no sexista.

$\mathrm{Su}$ actividad se califica en ocasiones mediante predicados con propiedades tales como la agresividad, la obstinación o la dureza, susceptibles de provocar reacciones negativas. Estos textos, por ejemplo, no solo destacan lo ilógico de determinadas propuestas inclusivas; también achacan, mediante empecinarse y resistirse a la evidencia, un alto grado de terquedad a quienes las plantean:

46) Es cosa tan clara y ya tantas veces repetida - con escasa eficacia, a lo que pareceque no valdría la pena volver sobre ella si no se hubiera producido, en las estrategias de quienes se resisten a aceptar evidencia tan inconcusa, una última vuelta de tuerca que sí puede merecer comentario (Álvarez de Miranda, 2016).

47) En Los académicos y las académicas (EL PAÍS, 12 de octubre), Jesús Ruiz Mantilla da cuenta del enésimo episodio en "la más que civil batalla" (diría Juan de Mena) de quienes rechazan por sexista el uso natural y espontáneo del castellano y se empecinan en introducir especificaciones tan artificiales, tan insensatas como "nosotros y nosotras" (Rico, 2016). 
En estos otros resulta obvio que los predicados basados en metáforas bélicas (echar toda la artillería, luchar, cargar contra, atacar, acuchillar) atribuyen a sus sujetos un grado considerable de agresividad y dureza respecto al informe de Bosque o directamente a la Academia:

48) La Directora del Instituto Andaluz de la Mujer, Soledad Ruiz, quien cargó duramente contra la RAE porque, según ella, dicha institución intentaba "invisibilizar a las mujeres (Cabello Pino, 2019, p. 10).

49) No fueron pocos precisamente quienes se lanzaron a comentar, responder o directamente atacar a través de los medios de comunicación al "Informe Bosque" tras únicamente una primera lectura apasionada del texto (Cabello Pino, 2019, p. 13).

50) Otros aludidos acuchillaban al amanecer y al atardecer el informe de la RAE (Astorga, 2012).

51) En lugar de luchar contra la estructura del idioma (que ninguna Academia, presente o pasada, podría establecer jamás), a mí me parece más importante luchar por la igualdad de salarios [...] (Vaquero, 2016) ${ }^{17}$.

52) Ayer Villanueva lamentó en conversación telefónica que Calvo hubiera echado "toda la artillería" en público y que aún no se hubiese puesto en contacto con él (Seisdedos, 2018).

Todo lo visto en este apartado viene a corroborar que parte del componente evaluativo que aportan los predicados cuando se argumenta sobre los desdoblamientos y los recursos gramaticales inclusivos se refiere explícitamente a elementos del ámbito lingüístico. Pero se ha evidenciado asimismo que la valoración que acarrean los predicados comentados no se limita a cuestiones gramaticales; se hace extensiva a las actitudes, el comportamiento, las ideas de las personas o instituciones que las sustentan. Tampoco, como se verá en el siguiente apartado, las valoraciones que proyecta la "otra parte" se ciñen a lo lingüístico; de ahí que, por ejemplo, en el manifiesto de apoyo a Bosque se reproche a quienes abogan por extender el lenguaje inclusivo que lo hagan "atacando" con descalificaciones morales y profesionales:

53) Lo que no es aceptable es que se pida que los lingüistas apoyen reglas que no son de su competencia y que además se han establecido sin atender a sus criterios, al tiempo que se hacen juicios morales precipitados sobre los miembros de este grupo (Fábregas et al., 2012).

54) $[\ldots]$ críticas feroces que incluyen insinuaciones sobre la integridad profesional del autor del informe, cuando no juicios morales inaceptables sobre él y, por extensión, quienes apoyan el contenido de su informe. (Fábregas et al., 2012).

\section{En la órbita de la defensa de los desdoblamientos y el lenguaje inclusivo}

No puede sorprender que las dos posturas polarizadas en torno a las propuestas gramaticales coincidan en algunos componentes de los predicados verbales que proyectan valoraciones negativas sobre la "otra parte".

Llamas Saíz (2015, p. 203) indicaba, por ejemplo, que se puede "presentar de manera negativa a las personas responsables de las guías señalando que se sienten

${ }^{17}$ Son palabras de Ignacio Bosque en entrevista publicada por Natalia Vaquero en La Opinión. A Coruña (27-11-2016). 
molestas por el uso del genérico masculino", suponiendo, claro, que esa reacción emotiva carezca de fundamento. Puede interpretarse, por tanto, que también estos textos presentan de forma negativa a quienes se "perturban" o se "mosquean" sin que haya justificación para ello:

55) Hay toda una política de lenguaje, a nivel tanto lingüístico como sociológico y de consumo plural, hay una ideología aplicada que, claro, cuando haces experimentos como el femenino plural hay quien se mosquea (Mohorte, 2016).

56) La utilización de dos géneros gramaticales es una de las prácticas que recomiendan las guías de lenguaje no sexista para ayudar a visibilizar a las mujeres. A Homero no le perturbó la reiteración, pero a la mayoría de los académicos sí (Alberdi, 2012b).

Partidarios de una y otra postura coinciden asimismo en utilizar predicados con componentes significativos de agresividad, dureza, para referirse al comportamiento de "los otros". Los textos que se incluyen más abajo, por ejemplo, sugieren un entorno de metáfora bélica en el que el lenguaje inclusivo se conceptualiza como un campo de batalla en el que luchan contendientes con posiciones no solo lingüísticas, sino también ideológicas (conservadoras vs. progresistas) distintas (Becker, 2019, p. 13).

El informe académico, su autor, la Academia, "arremeten" contra las guías, las "combaten", "cargan contra" ellas; es decir, sus acciones se presentan a través de predicados que connotan beligerancia ${ }^{18}$, agresividad, dureza y "cierta violencia dialéctica" (Sánchez García, 2009, p. 595):

57) "Sexismo y visibilidad de la mujer" es el título de este informe que carga contra las guías de lenguaje no sexista publicadas por diversas instituciones públicas españolas (Vilella, 2012).

58) Hace varios años, el catedrático Ignacio Bosque arremetió contra la mayoría de ellas [las guías] y contra un fenómeno, a juicio de todos los firmantes de su artículo, que pasaba por alto la recomendación de los más elementales criterios lingüísticos (Mohorte, 2016).

59) Visibilizo la que creo razón fundamental por la que la RAE combate las guías para aconsejar un lenguaje inclusivo y no sexista que no es otro que su progresiva implantación en la sociedad (López Díaz, 2012).

Hay coincidencia asimismo en achacar a los otros (en este caso, a la Academia) un grado considerable de obstinación, de terquedad, en el rechazo de las propuestas ("sigue empecinada", demuestra o manifiesta "férrea" o "enconada" resistencia):

60) Y para terminar, creo que la RAE ha llegado tarde al debate y sería un error que, reconociendo ya que determinadas expresiones lingüísticas son sexistas, siguiera empecinada en deslegitimar irónicamente expresiones inclusivas que, cada vez más, se están imponiendo en el lenguaje (López Díaz, 2012).

61) Las arrebatadas defensas del masculino de algunos de sus miembros y las diversas explicaciones, argumentos y apologías a favor del masculino [...] demuestran, en primer lugar, lo relativamente extendido de su uso y, en segundo lugar, la enconada resistencia de las Academias a su utilización (Bengoechea, 2012).

\footnotetext{
18 Violeta Demonte, en entrevista publicada por Ricardo Soca en El castellano.org (Soca, 2012), atribuye al informe de la Academia un ánimo especialmente "beligerante".
} 
62) El informe académico manifiesta una férrea resistencia a considerar "el uso abusivo del masculino genérico" y a aceptar las propuestas o alternativas no sexistas, si no como necesarias, al menos como opciones válidas en general y gramaticalmente correctas (Medina Guerra, 2016, p. 187).

Comparten igualmente el recurso a predicados que significan "causar destrucción o daño", si bien ese papel destructor se asigna ahora al lenguaje sexista o a quienes parecen apoyarlo, mientras las mujeres y sus avances sociales se presentan como afectados:

63) Bengoechea va un paso más allá y ve el texto como "parte de una campaña para destruir los avances de la mujer" (Vilella, 2012).

64) El lenguaje sexista es tan torpe que no solo excluye los términos que designan a las mujeres en grupos mixtos -como diputados y diputadas- sino que las maltrata simbólicamente, estereotipándolas en papeles de víctimas y folclóricas, y disminuyendo sus logros en todos los ámbitos en los que están ya presentes (López Díaz, 2012).

Por último, tampoco faltan desde "esta parte" del debate textos con construcciones que sugieren engaño, encubrimiento, discordancia entre los objetivos manifiestos de "los otros" (teóricamente preservar el funcionamiento normal de la lengua) y las intenciones inmovilistas, socialmente conservadoras, que realmente se le suponen. Ese contraste queda de manifiesto en el siguiente enunciado, por ejemplo, mediante el verbo disimular y la construcción con el predicativo resultativo "apolítica, neutral y normal":

65) La dimensión política de esta argumentación es obvia, aunque la propia postura conservadora se disimula y se construye como apolítica, neutral y normal (Becker, 2019, p. 13).

En este otro, la distancia entre las declaraciones de la RAE y lo que, a juicio de la autora, sugiere su actividad rea ${ }^{19}$ se expresa mediante desdecir y el adjetivo supuesto como evidencial:

66) Trato de desactivar las declaraciones, políticamente correctas, del supuesto compromiso de la RAE con la igualdad y contra la discriminación sexual; y recojo comportamientos y actuaciones que desdicen lo que afirman (López Díaz, 2012).

Queda, pues, claro que hay coincidencias en los componentes que se incorporan a la evaluación de la "otra parte" vehiculada por los predicados. No obstante, si antes se destacaba que parte de las valoraciones contenidas en la argumentación contra del recurso abusivo a los desdoblamientos y otras fórmulas inclusivas se ceñían al ámbito lingüístico, ahora los textos parecen situar en un primer plano aspectos ideológicos y sociales; de conformidad con ello, los juicios negativos tienen también por objeto las entidades que critican o tratan de limitar el alcance de las propuestas, así como las repercusiones de su rechazo en la sociedad y los colectivos que la integran ${ }^{20}$.

\footnotetext{
${ }^{19}$ Diferencia ya apuntada en el título mismo del artículo mediante el uso evidencial de decir: "Dice la RAE que está por la igualdad entre hombres y mujeres".

${ }^{20}$ Algo similar sugiere Guerrero Salazar (2019, p. 57) respecto a los debates sobre el sexismo en el diccionario.
} 
En efecto, se habrá podido observar que en los enunciados antes citados las evaluaciones negativas vehiculadas por los predicados se proyectaban sobre el informe de Bosque, los académicos, la Academia y el efecto perjudicial que sus propuestas y actitudes podían tener sobre el colectivo de las mujeres, sus logros sociales, su objetivo legítimo de alcanzar la igualdad. En los que se citan a continuación los predicados aportan juicios negativos sobre las normas gramaticales $\mathrm{y}$, por extensión, sobre las lenguas, pero, en línea con la tendencia que antes se ha subrayado, las valoraciones no se fundamentan en argumentos gramaticales; se basan en el modo en que afectan al estatus de la mujer en la sociedad: la invisibilizan, la oscurecen, la infravaloran, la excluyen, la subordinan, discriminan, denigran... Es decir, la sitúan en una posición desigual respecto al hombre, minimizan, hasta el punto de hacerla desaparecer, su participación en la sociedad:

67) No podemos hablar, entonces, de lenguaje sexista, sino de sexismo lingüístico, entendido como el conjunto de prácticas de lenguaje que realizan los seres humanos que invisibilizan, excluyen o discriminan tanto a las mujeres como a los grupos de diversidad sexual, social y étnica (Piña Laynes y González Poot, 2018, p. 375).

68) Todas las lenguas del planeta tienen mecanismos sexistas que discriminan, invisibilizan o subordinan a las mujeres (Riera, 2019) ${ }^{21}$.

69) Basta escuchar con intención cualquier conversación cotidiana [...] para descubrir que el lenguaje habitual está lleno de expresiones y estructuras que en el mejor de los casos perpetúan estereotipos que perjudican o invisibilizan a las mujeres y en el peor las denigran (Rius, 2014).

70) Hay dos tipos de sexismo en el lenguaje: las bromas, chistes y expresiones machistas, y el derivado del hecho de que el lenguaje tenga unas formas de hablar que oscurecen la presencia de las mujeres y dan prioridad a la realidad de los hombres (Rius, 2014).

En el siguiente texto el objeto de la nota negativa asociada a visibilizar "más al hombre que a la mujer" se relaciona con los dos pilares de la obra académica: el diccionario, la gramática y las obras que siguen su estela, de manera que se podría entender como un reproche implícito a la Academia; no obstante, la base sigue siendo el efecto minimizador del papel de la mujer en la sociedad y el juicio negativo que conlleva:

71) Hemos de dejar constancia de que, de forma consciente o no, lo cierto es que el diccionario académico visibiliza indudablemente más al hombre que a la mujer. Un proceso análogo tendrá lugar también en las obras gramaticales (Cabeza Pereiro y Rodríguez Barcia, 2013: 24).

En cualquier caso, abundan los enunciados en los que la apreciación negativa recae ya de forma explícita sobre el proceder de la Academia como institución y sobre quienes la integran. Así los enunciados que se citan a continuación contienen predicaciones que atribuyen al informe de Bosque, a los académicos, a la Academia, componentes de "manera" acordes con la actitud prepotente, el machismo, la misoginia, el anacronismo, etc., que, según se indicaba en los inicios de este trabajo, asociaban algunos de los "defensores del feminismo" a la Academia.

Eulàlia Lledó, en entrevista publicada por Mónica Zas Marcos en el.Diario.es (Zas Marcos, 2018), opina que la Academia piensa que "manda" sobre la lengua;

${ }^{21}$ Son palabras de Mercedes Bengoechea; se incluyen en la entrevista publicada por Mariola Riera en El día: Opinión de Tenerife. 
en los siguientes textos la ironía que sugiere el rechazo a la posibilidad de "equivocarse" y el uso asimismo irónico de "se han atrevido" acentúan la valoración negativa de la actividad académica por su defensa de la "ideología de la supremacía masculina" y la certeza de su propia autoridad que percibe amenazada:

72) La RAE parece olvidar que es una institución humana (financiada en parte por nuestros impuestos), no divina, y puede incluso, aunque a sus miembros les parezca imposible, equivocarse (Bengoechea, 2012).

73) Lo que verdaderamente les ha movido a publicar este Informe es querer restablecer el principio de autoridad que consideran socavado y que niegan a quienes se han atrevido a recomendar expresiones que benefician los cambios de la situación de las mujeres en la sociedad (López Díaz, 2012).

En estos otros se les achaca la intención de minar la relevancia de las propuestas gramaticales y su objetivo legítimo de visibilizar a la mujer en la sociedad; no solo tratan de "deslegitimar" o "desacreditar" las propuestas gramaticales inclusivas y su defensa; también "ridiculizan", "se mofan"; es decir, menosprecian, humillan:

74) "Está muy bien analizar las guías e identificar sus excesos, pero el manifiesto no hace solo eso sino que además niega la mayor y deslegitima la defensa del lenguaje inclusivo", dice (Vilella, 2012).

75) Se trata de desacreditar las posturas de quienes combaten la invisibilidad lingüística de las mujeres (Moreno Cabrera, 2012).

76) La extrañeza que suscitan ejemplos como los de (4) [...] invitan a una cierta prudencia ante las afirmaciones categóricas sobre el uso del masculino en el caso de nombres animados "para designar la clase que corresponde a todos los individuos de la especie" (RAE 2009: §2.2a) y, sobre todo, a la hora de desacreditar el uso de los desdoblamientos del tipo "los directivos y las directivas" (Cabeza Pereiro y Rodríguez Barcia, 2013, p. 17).

77) La propuesta que hacen algunas guías, de reiterar constantemente el masculino y el femenino de todo, no le gusta y lo ridiculiza. A mí tampoco, pero no me burlo porque el tema me parece muy serio (Alberdi, 2012a) ${ }^{22}$.

78) Pero también es cierto que han surgido voces en algunos blogs ridiculizando injustamente los esfuerzos de las autoras de las guías feministas (Uría, 2012).

79) Estos mismos individuos suelen mofarse de este lenguaje "artificioso" con ejemplos absurdos, del tipo: "Todos y todas los y las niños y niñas altos y altas de esta clase acudirán a las pruebas del equipo de baloncesto que están realizando los y las profesores y profesoras de Educación Física" (Gumiel Molina, 2019).

Los predicados de los textos siguientes sitúan en primer plano los juicios negativos asociados al inmovilismo o conservadurismo ${ }^{23}$ no solo lingüístico, sino también social ${ }^{24}$ e incluso político (Becker, 2019, pp. 12-13), a la ceguera, en definitiva, frente a los avances del feminismo.

\footnotetext{
22 Se refiere al informe de Bosque.

${ }^{23}$ Becker (2019) habla de "ideologemas conservadores" característicos del "pensamiento lingüístico academicista".

${ }^{24}$ Esa vertiente más social que lingüística queda patente, por ejemplo, en estas palabras de Cabeza Pereiro y Rodríguez Barcia (2013, p. 24) referidas al diccionario académico: "Sí se percibe una
} 
Así mientras "mujeres a quienes no conoce la RAE "tiran" de la lengua para poder sentirse incluidas, nombradas y visibles (Bengoechea, 2012), mientras las guías "tiran" asimismo "hacia una mayor feminización", la Academia, según afirma Demonte en entrevista publicada por Ricardo Soca (Soca, 2012), "no ha dado muestras de gran interés por la igualdad hombre-mujer"; antes bien, como institución "anacrónica e ideologizada" intenta, en opinión de Bengoechea (2012), "frenar esa transformación". Los siguientes textos apuntan evidentemente en ese mismo sentido:

80) [El proceder académico] manifiesta sin lugar a dudas un desajuste con respecto a la realidad social actual (Cabeza Pereiro y Rodríguez Barcia, 2013, p. 20).

81) Pero la RAE solo se rasga las vestiduras cuando las propuestas vienen de fuerzas progresistas en general y feministas en particular (Zas Marcos, 2018).

En este otro enunciado el pensamiento del autor se inserta en un marco hipotético, pero queda claro que ubica el informe de la RAE en una corriente reaccionaria que "pone en cuestión" los avances de las mujeres:

82) Si fuéramos malintencionados pensaríamos que el momento elegido por la RAE para publicar este informe no es casual y viene a coincidir con una corriente reaccionaria de puesta en cuestión de las conquistas de las mujeres en España durante los últimos 40 años (Reyes, 2012).

Resulta claro, por tanto, que en los textos de "esta parte" hay cierta tendencia a orientar sus valoraciones negativas sobre la "otra parte", más que hacia el ámbito lingüístico, hacia el terreno de las instituciones y la sociedad.

\section{Para concluir}

De conformidad con los objetivos planteados, en el desarrollo de este trabajo se ha ido describiendo el resultado del examen realizado sobre predicaciones verbales extraídas de un corpus de textos que reflejan posiciones encontradas a propósito de los recursos gramaticales encaminados a extender el lenguaje inclusivo, especialmente a propósito del "dobletismo". Se han destacado valoraciones negativas proyectadas por los predicados respecto a las propuestas gramaticales inclusivas, a quienes las rechazan o las sustentan y al efecto que pueda tener apoyarlas o ignorarlas en la sociedad y en la lengua. Se han ido subrayado asimismo algunas de las ideas subyacentes a tales valoraciones en las que parecen coincidir quienes sostienen posturas encontradas sobre esos temas.

Se ha visto que entre las ideas compartidas por quienes se sitúan en mayor o menor medida en la línea del informe de Bosque y la Academia, figuran valoraciones negativas que tienen por objeto el efecto de los dobletes y otras propuestas inclusivas en el sistema gramatical: constituyen una imposición artificial, contraria al funcionamiento natural de la lengua, y acarrean una serie de propiedades negativas ligadas a esa artificiosidad; entre ellas: complican innecesariamente las construcciones, conducen a errores gramaticales y malas interpretaciones, pueden deteriorar el sistema gramatical.

estrategia general, que podríamos enunciar como minimización de la mujer, materializada no solo a través de la ausencia de pares morfológicos sino también del mantenimiento de acepciones que acusan obsolescencia". 
Se ha visto asimismo que, como decía Demonte en la entrevista publicada en El castellano.org a la que antes se hizo referencia (Soca, 2012), aunque el problema tiene que ver con cuestiones gramaticales y normativas, "la cuestión trasciende bastante la gramática"; por tanto, ninguna de las partes se ciñe en sus juicios a lo estrictamente gramatical. En ambos casos la valoración se hace extensiva más allá de las propuestas lingüísticas a las personas e instituciones que las rechazan o la sustentan.

Ambas partes presentan coincidencias en algunas de las ideas que configuran la visión negativa de los otros, como la hipocresía, la falsedad, la discordancia entre los objetivos manifestados en relación con las propuestas relativas al lenguaje no sexista y los que se le suponen en realidad, o la dureza, la agresividad y la obstinación en la defensa de los planteamientos propios y el rechazo de las estrategias opuestas. Es perceptible asimismo que unos y otros achacan una tendencia a la imposición de los propios planteamientos sobre la otra parte, o sobre la sociedad y los hablantes.

No obstante, aunque los dos "bandos" trasciendan los límites de lo lingüístico y acaben valorando instituciones, colectivos, comportamientos, repercusiones sociales, quizá, como sugería Guerrero Salazar (2019, p. 57) a propósito de los debates sobre el sexismo del diccionario, en la defensa de las propuestas inclusivas se percibe más -al menos, en los textos examinados- el énfasis en las repercusiones sociales y los juicios negativos sobre el proceder de los colectivos e instituciones, la Academia y los académicos respecto a los esfuerzos para visibilizar, a través del lenguaje, a las mujeres y contribuir así a lograr la igualdad efectiva en la sociedad.

\section{Referencias}

1. Becker, L. (2019). Glotopolítica del sexismo: ideologemas de la argumentación de Ignacio Bosque y Concepción Company Company contra el lenguaje inclusivo de género. Theory Now Journal of Literature Critique and Thougt, 2(2), pp. 4-25. Recuperado de:

https://revistaseug.ugr.es/index.php/TNJ/article/view/9827 [Última consulta 17-102020]. DOI: https://doi.org/10.30827/tnj.v2i2.9827

2. Bengoechea, M. (2008). Lo femenino en la lengua: sociedad, cambio y resistencia normativa. Estado de la cuestión. Lenguaje y textos, 2(27), pp. 37- 68.

3. Bosque, I. (2012). Sexismo lingüístico y visibilidad de la mujer. Boletín de información lingüística de la Real Academia Española Recuperado de: http://www.rae.es/rae/Noticias.nsf/Portada3?ReadFormgmenu=3 [Última consulta 15/10/202].

4. Cabello Pino, M. (2019). Sobre sexismo lingüístico y visibilidad de la mujer (2012): lecturas imprecisas y tópicos infundados asociados al Informe Bosque. Archivum, 69, pp. 7-41. DOI: https://doi.org/10.17811/arc.0.2019.7-41

5. Cabeza Pereiro, M. C. y Rodríguez Barcia, S. (2013). Aspectos ideológicos, gramaticales y léxicos del sexismo lingüñistico. Estudios Filológicos, 52, pp. 7-27. DOI: https://doi.org/10.4067/S0071-17132013000200001

6. Díaz, J. A. (2011). Retórica periodística y controversias biopolíticas: El caso de la noticia sobre la polémica de las 'hamburguesas gigantes' (España, 2006). Revista Signos, 44(75), pp. 4-17. DOI: https://doi.org/10.4067/S0718-09342011000100002

7. Díaz Hormigo, M. T. (2018). Repercusiones y vigencia del uso de las propuestas para evitar la denominada discriminación lingüística por razón de sexo. En Díaz, M. et al. (Eds.), Actas do XIII Congreso Internacional de Lingüística Xeral (pp. 267-274). Vigo: Universidad de Vigo.

8. Fábregas, Antonio, et al. (2012). Acerca de la discriminación de la mujer y de los lingüistas en la sociedad: manifiesto de apoyo a D. Ignacio Bosque, 06-03-2012. Recuperado de: http://manifiestolinguistica.weebly.com/index.html

9. Guerrero Salazar, S. (2010). El sexismo lingüístico. Un tema de actualidad. Revista de 
divulgación científica de la Universidad de Málaga, 3, pp. 32-33.

10. Guerrero Salazar, S. (2019). Las demandas a la RAE sobre el sexismo del diccionario. La repercusión del discurso mediático. Doxa Comunicación, 29, pp. 43-60. DOI: https://doi.org/10.31921/doxacom.n29a2

11. Llamas Saíz, C. (2013). La actitud ante la lengua en el discurso de la prensa española: léxico y argumentación a propósito del sexismo lingüístico. En Llamas Saíz, C., Martínez Pasamar, C. y Casado Velarde, M. (Eds.), Léxico argumentación en el discurso público actual (pp. 187-208). Frankfurt: Peter Lang. DOI: https://doi.org/10.3726/978-3-653-01889-9

12. Llamas Saíz, C. (2015). Academia y hablantes frente al sexismo lingüístico: ideologías lingüísticas en la prensa española, Circula I, pp. 196-2015.

DOI: https://doi.org/10.17118/11143/7995

13. Marimón Llorca, C. y Santamaría Pérez, I. (2019). Introducción: Ideologías sobre la lengua en el mundo hispánico.En Marimón Llorca, C. y Santamaría Pérez, I. (Eds.), Ideologías sobre la lengua y medios de comunicación escritos. El caso del español (pp. 1-11). Berlin: Peter Lang. DOI: https://doi.org/10.3726/b15242

14. Martin, J. R. y White, P.R.R. (2005). The languaje of Evaluation. Appraisal in English. Basingstoke: Palgrave MacMillan. DOI: https://doi.org/10.1057/9780230511910

15. Medina Guerra, A. M. (2016). Las alternativas al masculino genérico y su uso en el español de España. Estudios de Lingüística Aplicada, 34(64), pp. 183-205.

16. Mendívil Giró, J. L. (2013). No permita que el sexo de los árboles le impida ver el género del bosque. Zaragoza Lingüistica. Seminario permanente de divulgación de la investigación lingüistica. Grupo Psylex (Universidad de Zaragoza). Recuperado de: https://zaragozalinguistica.wordpress.com/2013/03/20/no-permita-que-el-sexo-delos-arboles-le-impidan-ver-el-genero-del-bosque/T_[Última consulta 12-10-2020]. DOI: https://doi.org/10.31810/RSEL.50.1.2

17. Mendívil Giró, J.L. (2020). El masculino inclusivo en español. Revista Española de Lingüistica, 50(1), pp. 35-64.

Moreno Cabrera, J. C. (2012). Acerca de la discriminación de la mujer y de los lingüistas en la sociedad. Reflexiones críticas. Recuperado de:

http://www.pensamientocritico.org/juamor0915.pdf [Última consulta 20-10-2020].

18. Piña Laynes, A. A. y González Poot, A. A. (2018). De diatribas y diálogos sobre el lenguaje sexista, Cambios y permanencias, 9(2), pp. 372-385.

19. Roca, I. (2012): Algunas reflexiones críticas sobre: 'Acerca de la discriminación de la mujer y de los lingüistas en la sociedad'. GELA. Recuperado de:

http://www.gela.cat/lib/exe/fetch.php?id=textos_genere\&cache=cachegmedia=gen eroreflexionescriticasjcmc14may12.pdf [Última consulta 21-10-2020].

20. Saeger, B. de (2007). Evidencialidad y modalidad epistémica en los verbos de actitud proposicional en español. Interlingüística, 17, pp. 268-277.

Sánchez García, F. J. (2009). Estudio pragmático del discurso periodístico político español. A propósito de los debates sobre el estado de la Nación. Tesis doctoral. Granada: Universidad de Granada. Recuperado de:

https://digibug.ugr.es/bitstream/handle/10481/2703/18426074.pdf?sequence=18isAll owed=y [Última consulta 25/10/2020].

21. Torner, S. (2016). Los adverbios evidenciales en español. En González Ruiz, R., Izquierdo Alegría, D. y Loureda Lamas, Ó. (Eds.), La evidencialidad en español: teoría y descripción (pp. 251-276). Madrid/Frakfurt: Iberomaericana/Vervuert. DOI: https://doi.org/10.31819/9783954878710-010

\section{Blogs, columnas y artículos de prensa}

1. Alberdi, I. (2012a). Pero, ¿dónde estaba la RAE?. El País, 05-03-2012. Recuperado de: https://elpais.com/cultura/2012/03/05/actualidad/1330979981_863178.html [Última consulta 15-10-2020].

2. Alberdi, I. (2012b). Son un poco antiguos en la RAE. El País, 30-07-2012. Recuperado de: https://elpais.com/sociedad/2012/07/30/actualidad/1343676381_917439.html [Última consulta 10-10-2020].

3. Álvarez de Miranda, P. (2018a). Feminismo y gramática. El País, 11-02-2018. Recuperado de: 
https://elpais.com/elpais/2018/02/10/opinion/1518289605_377728.html

[Última consulta 15-09-2020].

4. Álvarez de Miranda, P.(2018b). "¿Una constitución "bigénero"?", El País, 27-07-2018. Recuperado de:

https://elpais.com/elpais/2018/07/19/opinion/1532016490_743662.html

[Última consulta 15-10-2020].

5. Alvarez de Miranda, P. (2016). "Nosotras venimos dispuestos". El País, 06-09-2016. Recuperado de:

https://elpais.com/elpais/2016/09/05/opinion/1473088930_657891.html [Última consulta 15-10-2020].

6. Astorga, A. (2012). Compañeros y compañeras del metal... lingüístico. ABCdesevilla.es 05-03-2012. Recuperado de:

https://sevilla.abc.es/20120305/cultura/abci-companeros-companeras-metallinguistico-201203051430.htm [Última consulta 02-10-2020].

7. Azofra Sierra, E. (2012). Género gramatical y sexismo (II): los corsés del femenino, Morfolog, 08-03-212. Recuperado de: https://morflog.hypotheses.org/541 [Última consulta 02-10-2020].

8. Bengoechea, M. (2012). La sociedad cambia, la Academia no. El País, 7-03-2012). Recuperado de:

https://elpais.com/elpais/2012/03/07/mujeres/1331101860_133110.html [Última consulta 02-10-2020].

9. Del Corral, M. (2012). "No veo qué ganamos las mujeres". El País, 05-03-2012. Recuperado de:

https://elpais.com/cultura/2012/03/05/actualidad/1330978173_276626.html [Última consulta 02-10-2020].

10. Escolar, A. (2018). Darío Villanueva: 'El idioma es un ecosistema. Si se altera de manera arbitraria, se deteriorará, Archiletras, 05-11-2018. Recuperado de: https://www.archiletras.com/actualidad/dario-villanueva-entrevista/ [Última consulta 04-10-2020].

11. García Pérez, F. (2012). A vueltas con el sexismo lingüístico. La Opinión de Murcia, 2503-2012. Recuperado de:

https://www.laopiniondemurcia.es/opinion/2012/03/25/vueltas-sexismolinguistico/394361.html [Última consulta 02-10-2020].

12. Grijelmo, Á. (2018a). Catalanes excluidos, El País, 10-06-2018. Recuperado de: https://elpais.com/elpais/2018/06/08/opinion/1528455956_458355.html [Última consulta 07-10-2020].

13. Grijelmo, Á. (2018b). ¿Invisibiliza nuestra lengua a la mujer?. El País, 02-12-2018. Recuperado de:

https://elpais.com/cultura/2018/11/28/actualidad/1543418937_639835.html [Última consulta 07-10-2020].

14. Grijelmo, Á. (2020). Duplicaciones discriminatorias, El País, 27-03-2020. Recuperado de: https://elpais.com/ideas/2020-03-27/duplicaciones-discriminatorias.html[Última consulta 07-10-2020].

15. Gumiel Molina, S.(2019). Es sexista la lengua española. EL COMERCIO, 08-03-2019. Recuperado de:

https://www.elcomercio.es/dia-de-la-mujer/sexista-lengua-espanola-diainternacional-mujer-8-marzo-20190308110908-nt.html [Última consulta 03-10-2020].

16. Lindo, E. (2012). Quiero. El País, 07-03-2012. Recuperado de: https://elpais.com/elpais/2012/03/06/opinion/1331055728_922838.html [Última consulta 03-10-2020].

17. López Díaz, P. (2012). Dice la RAE que está por la igualdad entre hombres y mujeres. Sobre el Informe Sexismo lingüístico y visibilidad de la mujer. Mujeres en red, 032012. Recuperado de: http://www.mujeresenred.net/spip.php?article1952[Última consulta 06-10-2020].

18. Lucio, A. (2017): El uso normal del género gramatical no es lenguaje sexista, Socied@adReticular, 27-04-2017. Recuperado de:

https://anselmolucio.wordpress.com/2017/04/27/el-uso-normal-del-generogramatical-no-es-lenguaje-sexista/comment-page-1/ [Última consulta 04-10-2020]. 
19. Manrique Sabogal, W. (2012). ¿La lengua tiene género? ¿Y sexo?. EL País, 05-03-2012. Recuperado de:

https://elpais.com/cultura/2012/03/04/actualidad/1330896843_065369.html [Última consulta 06-10-2020].

20. Mohorte, A. P. (2016). Ellos, ellas y la RAE: el debate del sexismo y el lenguaje. Magnet, 29-01-2016. Recuperado de: https://magnet.xataka.com/en-diez-minutos/ellos-ellasy-la-rae-el-debate-del-sexismo-y-el-lenguaje [Última consulta 07-10-2020].

21. Moure, J. L. (2018): Lenguaje inclusivo. Blog del V Congreso Internacional de Correctores de Estilo en Español. Recuperado de:

https://5cictecongresocorrectores.wordpress.com/2018/09/03/lenguaje-inclusivo/ [Última consulta 09-10-2020].

22. Remacha, B. (2016).Golondrinas feministas invaden la RAE, elDiario.es, 25-04-2016. Recuperado de:

https://www.eldiario.es/cultura/feminismo/golondrinas-rae-escrache-machismodiccionario_1_4042266.html [Última consulta 05-10-2020].

23. Reyes, P. (2012). Lenguaje sexista y RAE (El árbol que no permite ver el bosque). nuevatribuna.es, 06-03-2012. Recuperado de:

https://www.nuevatribuna.es/opinion/author/lenguaje-sexista-y-rae-el-rbol-queno-permite-ver-el-bosque/20120306123348071470.html [Última consulta 11-10-2020].

24. Rico, F. (2016). Las académicas y los académicos, El País, 14-10-2016. Recuperado de: https://elpais.com/cultura/2016/10/13/actualidad/1476377157_913599.html [Última consulta 10-10-2020].

25. Riera, M. (2019). Todas las lenguas discriminan a la mujer. Entrevista a Mercedes Bengoechea, El día. Opinión de Tenerife, 22-12-2019. Recuperado de:

https://www.eldia.es/dominical/2019/12/22/lenguas-discriminan-mujer22505719.html [Última consulta 07-10-2020].

26. Rius, M. (2014). El sexismo que ocultan las palabras. La Vanguardia, 07/03/2014. Recuperado de:

https://www.lavanguardia.com/estilos-de-vida/20140307/54402851720/el-sexismoque-ocultan-las-palabras.html [Última consulta 13-10-2020].

27. Roca, I. (2016). El "juego" del doblete. El País, 20-02-2016. Recuperado de: https://elpais.com/elpais/2016/02/19/opinion/1455881505_979498.html [Última consulta 05-10-2020].

28. Ruiz Mantilla, J. (2016). Los académicos y las académicas discuten sobre sexismo lingüístico, El País, 19-10-2016. Recuperado de:

https://elpais.com/cultura/2016/10/11/actualidad/1476204624_012306.html [Última consulta 06-10-2020].

29. Ruiz Mantilla, J. (2019). El lenguaje inclusivo tensa a 'todes' en Argentina. El País, 3003-2019. [Última consulta 05-10-2020]. Recuperado de: https://elpais.com/cultura/2019/03/30/actualidad/1553959465_205850.html [Última consulta 05-10-2020].

30. Seisdedos, I. (2018). Dario Villanueva: 'El problema está en confundir la gramática con el machismo. El País, 16-07-2018. Recuperado de:

https://elpais.com/cultura/2018/07/15/actualidad/1531677196_003986.html [Última consulta 11-10-2020].

31. Soca, R. (2012). Las academias no hacen falta para la unidad de la lengua. Entrevista Violeta Demonte. El castellano.org, 26-03-212. Recuperado de:

https://rebelion.org/las-academias-no-hacen-falta-para-la-unidad-de-la-lengua/ [Última consulta 13-10-2020].

32. Uría, P. (2012). La polémica sobre el sexismo lingüístico. Página Abierta, 12-03-2012. Recuperado de: http://www.pensamientocritico.org/paluri0412.htm [Última consulta 05-10-2020].

33. Vaquero, N. (2016). Creemos que el masculino genérico no es discriminatorio. Entrevista a Ignacio Bosque, La Opinión.A Coruña, 27-11-2016. Recuperado de: https://www.laopinioncoruna.es/sociedad/2016/11/27/creemos-masculinogenerico-discriminatorio/1129335.html [Última consulta 05-10-2020].

34. Vilella, P. (2012). ¿Es sexista el idioma español?. BBC News. Mundo, 08-03-2012. Recuperado de: 
$\operatorname{ASI}(\mathrm{E} \quad$ tep

https://www.bbc.com/mundo/noticias/2012/03/120308_sexismo_idioma_espanol/ [Última consulta 08-10-2020].

35. Zas Marcos, M. (2017). Las académicas de la RAE quieren dar "un esplendor feminista" al lenguaje. elDiario.es, 06-04-2017. Recuperado de:

https://www.eldiario.es/cultura/academicas-rae-esplendor-feministalenguaje_1_3480004.html [Última consulta 08-10-2020].

36. Zas Marcos, M. (2018). La RAE tiene la idea curiosa de que manda sobre la lengua y eso es demoledor. Entrevista a Eulàlia Lledó. elDiario.es, 19-08-2018. Recuperado de: https://www.eldiario.es/cultura/eulalia-lledo-rae-lengua-

demoledor_128_2018270.html [Última consulta 08-10-2020]. 